\title{
Una nueva Sociedad Uruguaya de Cardiología en lo gremial, laboral y profesional
}

En los últimos años la Sociedad Uruguaya de Cardiología (SUC) ha estado abocada a participar activamente en los ámbitos profesionales, laborales y gremiales de nuestra especialidad.

Realizamos un modelo de cargos de alta dedicación en las instituciones privadas, y estamos promoviendo la creación de funciones de alta dedicación (FAD) en la Administración de los Servicios de Salud del Estado con buena respuesta por parte de las autoridades. Ya están en curso varios llamados de FAD en Montevideo y en el interior del país cuyas condiciones tienen que ser avaladas por la SUC.

Se elaboró una propuesta de laudos de la especialidad y de casi todas las subespecialidades que será tema del Consejo de Salarios, pensamos que laudar condiciones de trabajo y remuneración será una garantía para mantener la calidad del trabajo de los cardiólogos y la excelencia en la asistencia de los pacientes, será la base sobre la que las futuras generaciones de cardiólogos puedan mejorar lo que hemos realizado.

El Sindicato Médico del Uruguay (SMU) actualmente es el interlocutor con el que las autoridades acuerdan los principales temas gremiales y laborales. En este sentido, la Comisión de Asuntos Laborales de la SUC está trabajando activamente y en colaboración mutua con la Unidad de Negociación Colectiva del SMU abordando varios problemas laborales.

Nos preocupa la progresiva tercerización y precarización del trabajo cardiológico, fundamentalmente cuando implica un deterioro de las condiciones de trabajo para los colegas más jóvenes y pérdida de fuentes laborales, que en muchos casos tienen una amplia trayectoria en la especialidad y en las distintas subespecialidades. Con una mirada rápida parecería que se están perdiendo los mínimos requerimientos éticos de relacionamiento profesional entre colegas, pero entendemos que este es un tema complejo de diagnosticar y resolver. La respuesta tiene que surgir de todo el colectivo médico, nos debemos una franca discusión en la que acordemos aspectos éticos y profesionales básicos de nuestro relacionamiento laboral: ¿hasta qué límite es correcto ofrecer un mejor negocio para quedarnos con el trabajo de nuestros colegas? ¿Cuánto vale nuestro trabajo y en qué condiciones vamos a ejercerlo? Las preguntas están arriba de la mesa, las respuestas no parecen lejanas.

En el aspecto profesional la Comisión de Educación Médica Continua retomó este año con éxito y con gran receptividad sus actividades y está sentando las bases para la recertificación en nuestra especialidad. La SUC continúa siendo un ejemplo y un modelo a seguir en cómo realizar educación médica continua.

Consideramos de gran importancia mejorar las oportunidades de formación y de investigación, para esto hemos continuado mejorando significativamente los convenios con sociedades científicas extranjeras. Estos convenios con la Sociedad Europea de Cardiología, el Colegio Americano de Cardiología y la Sociedad Española de Cardiología brindan oportunidades de becas de intercambio, asistencia sin costo a congresos, acceso a revistas científicas y producción de trabajos científicos. Nuestra motivación es mejorar las oportunidades de abrirnos al mundo.

Consideramos que fue un año muy productivo y los logros fueron posibles por el excelente equipo de trabajo que hemos tenido en la Comisión Directiva, en el Consejo Editorial de la Revista Uruguaya de Cardiologia y en las distintas comisiones y comités de la SUC.

\author{
Dr. Álvaro Niggemeyer \\ Presidente de la Sociedad Uruguaya de Cardiología
}

